\title{
Genetic Analysis of Pyricularia grisea Population by rep-PCR During Development of Resistance to Scytalone Dehydratase Inhibitors of Melanin Biosynthesis
}

Fumihiko Suzuki and Michiyoshi Arai, National Agricultural Research Center for Kyushu Okinawa Region, 2421 Suya, Koshi, Kumamoto 861-1192, Japan; and Junichiro Yamaguchi, 2 Saga Agricultural Experiment Research Center, Saga-gun Saga 840-2205, Japan

\begin{abstract}
Suzuki, F., Arai, M., and Yamaguchi, J. 2007. Genetic analysis of Pyricularia grisea population by rep-PCR during development of resistance to scytalone dehydratase inhibitors of melanin biosynthesis. Plant Dis. 91:176-184.

In 2001, field isolates of Pyricularia grisea resistant to scytalone dehydratase inhibitors of melanin biosynthesis (MBI-D) were reported in Saga prefecture, Kyushu. Among 1,175 isolates collected from six prefectures of Kyushu in 2002 and 2003, 647 were resistant to MBI-D fungicides, each due to a single point mutation of the scytalone dehydratase (SDH) gene. On the basis of repetitive element-based polymerase chain reaction (rep-PCR) fingerprint data, the haplotypes of the resistant isolates showed high genetic diversity, indicating that the resistance existed in a multigenetic background. Three predominant haplotypes mainly contributed to the widespread resistance in Kyushu; haplotype Sa4 was observed frequently in Saga, Sa18 was predominant in Oita and Miyazaki, and Sa5 was widely distributed among all four prefectures. Also, phylogenetic analysis showed that both the resistant and sensitive isolates were clustered together in a closely related group. These results suggest that isolates possessing the SDH mutation would have been selected and then multiplied rapidly in each region of Kyushu as a result of the widespread introduction of MBI-D fungicides in a short period.
\end{abstract}

Pyricularia grisea (perfect stage: Magnaporthe oryzae) $(4,25)$ is responsible for the most damaging fungal disease of rice, known as rice blast. For the management of this disease, carpropamid, one of the melanin biosynthesis inhibitors targeting scytalone dehydratase (MBI-D), was introduced to the market of Japan in 1998 as an effective fungicide providing long-term residual control (15-17). When applied to nursery boxes, this fungicide remains effective from planting until near the heading stage.

Enzyme kinetic data have shown that carpropamid is a tightly binding competitive inhibitor of scytalone dehydratase (SDH), a key enzyme in the biosynthesis of melanin $(19,20,22,35)$. If melanin biosynthesis is inhibited, the pathogen cannot exert its pathogenicity because fungal penetration into the host epidermis is inhibited through an appressorium $(1,2,9)$. Other types of melanin biosynthesis inhibitors targeting polyhydroxynaphthalene reductase (MBI-R), such as phthalide, tricyclazole, and pyroquilon, are also used for controlling the rice blast pathogen $(7,10,33)$. The occurrence of isolates resis-

Corresponding author: F. Suzuki

E-mail: fsuzuk@affrc.go.jp

Accepted for publication 8 September 2006.

DOI: 10.1094/PDIS-91-2-0176

(C) 2007 The American Phytopathological Society tant to MBI-R has never been reported in more than 30 years. In addition, these two types of melanin biosynthesis inhibitor are primarily nontoxic to the vegetative growth of $P$. grisea. Therefore, it was assumed that the risk of development of MBI-D resistance would be low. The use of carpropamid for nursery box application had spread to over $20 \%$ of paddies in Saga prefecture, Kyushu, by 2000.

However, failure of carpropamid to control rice blast was reported in Saga prefecture in 2001, and the occurrence of isolates resistant to MBI-D was first confirmed in this area (36). Subsequently, the resistant isolates spread throughout almost all of Kyushu in 2002 to 2003 (27). Prior to the present study, field resistance of $P$. grisea to carpropamid was associated with a single point-mutation of the SDH gene that resulted in replacement of valine by methionine at amino acid position 75 (V75M) (32). Carpropamid-resistant isolates showed cross-resistance to other melanin biosynthesis inhibitors targeting MBI-D, such as diclocymet and fenoxanil $(14,18)$, while sensitivity to MBI-R was unchanged $(27,29)$. It was confirmed that inhibition of the variant enzyme by carpropamid was reduced more than 200fold in comparison with that of the wildtype retaining the normal enzymatic activity (34). A method for diagnosis of MBI-D resistance has been established using primer-introduced restriction enzyme analysis polymerase chain reaction (PIRA-PCR) (13).
Although the mutation responsible for resistance to MBI-D fungicides was revealed in a previous study $(13,32)$, the genetic relationships between isolates possessing the same mutation in the SDH gene were not clear. One possibility is that isolates with the same mutation were derived from a single MBI-D-resistant progenitor. Alternatively, spontaneous mutation causing MBI-D resistance may have arisen frequently in the rice blast pathogen population. In this study, we selected the use of DNA fingerprinting analysis by repetitive element-based PCR (rep-PCR) to investigate the genetic background of the resistant isolates.

George et al. (8) applied rep-PCR using two outwardly directed primers designed from the sequence of the transposable element Pot2 (12)-designated as Pot 2 rep-PCR - to analyze the population structure of P. grisea. Pot 2 rep-PCR has advantages with respect to ease of application and low cost. This method has already been used in several studies for analyzing the population structure of $P$. grisea $(3,11,21)$. In a previous study, we modified the rep-PCR technique with regard to primer design, amplification conditions, and electrophoretic apparatus for characterizing a larger number of $P$. grisea isolates, and succeeded in establishing a convenient and simple DNA fingerprinting technique (31). The novel feature of our method was the use of a single primer complementary to a sequence in the terminal inverted repeat of Pot 2 .

The objectives of the present study were (i) to clarify the frequency of the MBI-D resistance gene in the pathogen population, (ii) to estimate the level of genetic diversity in the population of MBI-D-resistant isolates, and (iii) to reveal the distribution of haplotypes of MBI-D-resistant isolates in the Kyushu area. It was considered that data on these aspects would help to clarify the risk of resistance outbreaks in other locations, to determine whether resistance had spread to the entire area of Kyushu from Saga prefecture, and to consider the strategy for use of this fungicide class. Therefore, we collected a total of 1,175 $P$. grisea isolates from the Kyushu area, mainly Saga prefecture, during development of MBI-D resistance in the blast pathogen population, and performed DNA fingerprint analysis by rep-PCR using a single primer to determine the genetic 
backgrounds of isolates containing the SDH mutations conferring MBI-D resistance.

\section{MATERIALS AND METHODS}

Isolate collection and maintenance. Isolates of $P$. grisea were collected from rice in 2002 and 2003 from six prefectures of Kyushu-Saga, Fukuoka, Nagasaki, Kumamoto, Oita, and Miyazaki-where usage of MBI-D fungicides is widespread. Sampling locations were selected to analyze the genetic backgrounds of MBI-Dresistant isolates in the $P$. grisea populations; one was aimed at the area where resistance was first confirmed (Saga), and the other was aimed at a large geographic region of widespread resistance (Saga, Fukuoka, Nagasaki, Kumamoto, Oita, and Miyazaki) (Table 1). Most of the collections were made from farmer's paddy fields. At both locations, approximately five leaves with characteristic blast symptoms were sampled in each paddy field. Leaf blades with necrotic lesions were washed in tap water for 1 to $3 \mathrm{~min}$ and placed on moist filter paper in petri dishes for $24 \mathrm{~h}$ at $25^{\circ} \mathrm{C}$ in order to induce sporulation. Conidia were dislodged from individual sporulating lesions onto potato dextrose agar (PDA) plates. Monoconidial isolates were picked aseptically and transferred to fresh PDA plates. Filer paper disks were placed on the PDA plates, and the mycelium was allowed to grow over the disks. After the fungus had completely colonized the disks, they were removed from the culture plate and air-dried. The disks were then placed in sterilized vials and stored at $-20^{\circ} \mathrm{C}$. In July and August 2002, sampling was carried out arbitrarily at 102 sites in Saga prefecture, and a total of 404 isolates were obtained (Table 1). In July and August 2003, sampling was carried out arbitrarily at 138 sites in six prefectures, and a total of 771 isolates were obtained (Table 1).

DNA extraction. $P$. grisea isolates were grown in petri dishes containing potato dextrose broth (Difco Laboratories, Detroit, MI) at $25^{\circ} \mathrm{C}$ for 4 to 5 days. Mycelia were transferred to a microfuge tube, and total genomic DNA of the isolates was extracted using the Ultra Clean Microbial DNA Isolation kit procedure (MO BIO Laboratories Inc., Carlsbad, CA).

Method for diagnosis of MBI-D resistance in rice blast fungus. Screening for the V75M mutation was carried out based on primer-introduced restriction enzyme analysis PCR (PIRA-PCR) by addition of an $\mathrm{XbaI}$ restriction site for PCR products from MBI-D resistant isolates (13). Oligonucleotide primers for both SCDH4 (5' TTATTTGTCGCCAAAGGTCTCC 3') and SCDH13 (5' TTCGTCGGCATG GTCTCGAGCATCTAG 3') were designed by Kaku et al. (13) based on the P. grisea scytalone dehydratase gene sequence deposited in the EMBL database (accession no. AB004741). PCR was performed in a total volume of $20 \mu \mathrm{l}$ containing $1 \times$ reaction buffer $\left(\mathrm{Mg}^{2+}\right.$ plus) (Takara Bio Inc., Shiga, Japan), $200 \mu \mathrm{M}$ each dNTP, $0.5 \mu \mathrm{M}$ each primer, $10 \mathrm{ng}$ of genomic DNA, and 0.4 unit of Takara Taq (Takara Bio), which has no 3' to $5^{\prime}$ exonuclease activity. Cycling parameters were $94^{\circ} \mathrm{C}$ for $10 \mathrm{~min}$, followed by 40 cycles of $94^{\circ} \mathrm{C}$ for $1 \mathrm{~min}, 50^{\circ} \mathrm{C}$ for $1 \mathrm{~min}$, $72^{\circ} \mathrm{C}$ for $2 \mathrm{~min}$, and a final extension of $72^{\circ} \mathrm{C}$ for $5 \mathrm{~min}$. The PCR product $(2 \mu \mathrm{l})$ was digested with $X b a \mathrm{I}$, and the restriction fragments were resolved by electrophoresis in 3\% agarose gels (Seaplaque GTG agarose, FMC Bio, Rockland, ME).

Analysis of rep-PCR using the single primer method. The primer sequence was designed based on a part of the 43-bp terminal inverted repeat sequence in the repetitive element Pot 2 (EMBL accession Z33638), found in $P$. grisea. The primer Pot2-TIR (5' ACAGGGGGTACGCAA CGTTA $3^{\prime}$ ) was designed from the terminal inverted repeat sequence of Pot2 (31). PCR reactions were carried out in a $20-\mu l$ volume containing $10 \mathrm{ng}$ genomic DNA, $0.5 \mu \mathrm{M}$ Pot2-TIR primer, $400 \mu \mathrm{M}$ each $\mathrm{dNTP}, 1 \times$ Ex Taq buffer, $2 \mathrm{mM} \mathrm{MgCl}_{2}$, and 1 unit of Taq DNA polymerase (Takara Ex Taq) (Takara Bio). PCR amplifications were performed in a GeneAmp PCR System 9600 (Applied Biosystems, Foster City, CA) programmed for $2 \mathrm{~min}$ at $94^{\circ} \mathrm{C}$, followed by 35 cycles of $1 \mathrm{~min}$ at $94^{\circ} \mathrm{C}, 1$ min at $62^{\circ} \mathrm{C}, 6 \mathrm{~min}$ at $72^{\circ} \mathrm{C}$, final extension for $15 \mathrm{~min}$ at $72^{\circ} \mathrm{C}$, and holding at $4^{\circ} \mathrm{C}$. The PCR products were separated by electrophoresis on $1 \%$ agarose gels (Seakem GTG agarose, BioWhittaker Products, Rockland, ME) in $1 \times$ Tris-borate buffer (89 mM Tris, $89 \mathrm{mM}$ boric acid, $2 \mathrm{mM}$ EDTA). Gels were run for $1.5 \mathrm{~h}$ at $100 \mathrm{~V}$, and stained with ethidium bromide.

To determine the genetic relationships among isolates, the presence or absence of bands was converted into binary data ( 1 for presence and 0 for absence of each band). A matrix of similarities between all pairs of isolates was constructed based on a simple matching coefficient. Cluster analysis was performed on the similarity coefficients by the unweighted pair-group method with arithmetic averages (UPGMA) using the PHYLIP program (6). Bootstrap analysis of the data was performed with 1,000 replications using the WINBOOT program (37).

Haplotype diversity was calculated using the equation $H=n /(n-1)\left(1-\sum x_{i}^{2}\right)(23)$, in which $n(n-1)$ is a correction for bias in small samples (28) and $x_{i}$ is the frequency of $i$ th haplotype in the collection.

\section{RESULTS}

Gene diagnosis of resistance to MBI$D$ fungicides in $P$. grisea isolates from Saga prefecture in 2002. A total of 404 isolates of $P$. grisea were obtained by single-spore isolation from Saga prefecture in 2002. Using the PIRA-PCR method (13), the point-mutation was detected in 290 $(71.8 \%)$ of the isolates collected from 75 $(73.5 \%)$ of the sites (Table 1). Figure 1A shows the sampling sites in Saga prefecture in 2002, and the sites where MBI-Dresistant isolates were detected are represented by solid circles. These results indicated that MBI-D-resistant isolates occurred widely and frequently throughout Saga prefecture in 2002, especially in the western region (Fig. 1A).

DNA fingerprinting patterns detected by rep-PCR for $P$. grisea isolates from Saga prefecture in 2002. Using rep-PCR with the single primer Pot2-TIR, DNA fingerprints were obtained for 404 of the $P$. grisea isolates collected from Saga prefecture in 2002. Bands ranging in size from 0.3 to $5.8 \mathrm{~kb}$ and in number from 7 to 11

Table 1. Summary of diagnosis of resistance to melanin biosynthesis inhibitors that target scytalone dehydratase (MBI-D) and haplotype diversity of Pyricularia grisea sampled in Kyushu in 2002 and 2003 based on repetitive element-based polymerase chain reaction (rep-PCR) fingerprints

\begin{tabular}{|c|c|c|c|c|c|c|c|c|}
\hline \multirow{2}{*}{$\begin{array}{l}\text { Year and } \\
\text { Prefecture }\end{array}$} & \multicolumn{2}{|c|}{$\begin{array}{c}\text { No. of } \\
\text { sampling sites }^{a}\end{array}$} & \multicolumn{2}{|c|}{$\begin{array}{c}\text { No. of } \\
\text { isolates }^{b}\end{array}$} & \multicolumn{2}{|c|}{$\begin{array}{c}\text { No. of } \\
\text { haplotypes }^{c}\end{array}$} & \multicolumn{2}{|c|}{$\begin{array}{l}\text { Haplotype } \\
\text { diversityd }^{d}\end{array}$} \\
\hline & $\mathbf{T}$ & $\mathbf{R}$ & $\mathbf{T}$ & $\mathbf{R}$ & $\mathbf{T}$ & $\mathbf{R}$ & $\mathbf{T}$ & $\mathbf{R}$ \\
\hline \multicolumn{9}{|l|}{2002} \\
\hline Saga & 102 & 75 & 404 & 290 & 37 & 15 & 0.76 & 0.55 \\
\hline \multicolumn{9}{|l|}{2003} \\
\hline Saga & 64 & 46 & 286 & 158 & 35 & 18 & 0.88 & 0.80 \\
\hline Fukuoka & 13 & 6 & 57 & 32 & 12 & 5 & 0.86 & 0.76 \\
\hline Nagasaki & 4 & 2 & 21 & 13 & 4 & 2 & 0.73 & 0.54 \\
\hline Kumamoto & 15 & 2 & 110 & 30 & 13 & 4 & 0.60 & 0.58 \\
\hline Oita & 28 & 14 & 234 & 105 & 22 & 8 & 0.79 & 0.69 \\
\hline Miyazaki & 14 & 11 & 63 & 18 & 12 & 3 & 0.85 & 0.31 \\
\hline 2003 total & 138 & 81 & 771 & 356 & 64 & 28 & 0.86 & 0.87 \\
\hline $2002-2003$ total & 240 & 156 & 1,175 & 646 & 76 & 31 & 0.88 & 0.80 \\
\hline
\end{tabular}

${ }^{\mathrm{a}} \mathrm{T}=$ total number of sampling sites for each population; $\mathrm{R}=$ number of sites where resistant isolates were obtained.

b $\mathrm{T}=$ total number of isolates collected from each population; $\mathrm{R}=$ number of MBI-D-resistant isolates.

${ }^{\mathrm{c}} \mathrm{T}=$ number of haplotypes among total isolates detected by rep-PCR analysis; $\mathrm{R}=$ number of haplotypes observed among resistant isolates.

d Nei's measure of genetic diversity for each population based on frequencies of fingerprint haplotypes (23); $\mathrm{T}=$ diversity for entire isolates; $\mathrm{P}=$ diversity for resistant isolates. 
per strain were amplified. A total of 37 distinct fingerprint patterns (haplotypes designated as Sa1-37) were distinguishable (Fig. 2B). The numbers of sites isolated for each haplotype, combined with the data for MBI-D resistance diagnosis, were represented by a bar chart (Fig. 2A). The 290 of the resistant isolates were separable into 15 distinct haplotypes designated $\mathrm{Sa} 1, \mathrm{Sa} 4$, Sa5, Sa11, Sa17, Sa18, Sa20, Sa30, Sa31, Sa32, Sa33, Sa34, Sa35, Sa36, and Sa37 (Fig. 2A). This result indicates that the population of resistant isolates already possessed relatively high haplotypic diversity $(H=0.55$; Table 1$)$. Among these, haplotype $\mathrm{Sa} 4$ was observed at a high frequency in this population, being detected in 189 isolates $(46.8 \%)$ from 54 sites $(52.9 \%)$ and distributed throughout Saga prefecture (Fig. 1B). Therefore, the Sa4 haplotype appeared to be that which was predominant and mainly responsible for failure of MBI-D fungicides to control rice blast in Saga prefecture in 2002. Also, several haplotypes, such as Sa1 and Sa33, were detected at relatively high frequency among the resistant isolates, although they were much less frequent than Sa4. In addition, other haplotypes such as Sa5 and Sa11 included both resistant and sensitive isolates.

Gene diagnosis of resistance to MBI$D$ fungicides in $P$. grisea isolates from six prefectures of Kyushu in 2003. Gene diagnosis was carried out for 771 isolates collected from 138 sites in six prefectures of Kyushu in 2003: Saga, Fukuoka, Nagasaki, Kumamoto, Oita, and Miyazaki. The point-mutation of SDH conferring resistance to MBI-D was detected in 356 $(46.2 \%)$ of the isolates collected from 81 $(58.7 \%)$ of the sites (Table 1). Also, resistant isolates were observed in all six prefectures at relatively high frequency (Table 1). These results indicated that resistant isolates had already become distributed throughout Kyushu within only 2 years after the first confirmation in Saga.

Fingerprint analysis and distribution of MBI-D-resistant isolates from six prefectures of Kyushu in 2003. Rep-PCR analysis identified a large number of haplotypes from isolates collected from Kyushu in 2003; a total of 64 different haplotypes were identified among 771 isolates (Table 1). The numbers of sites for each haplotype detected from six prefectures are represented in Table 2. Common fin-

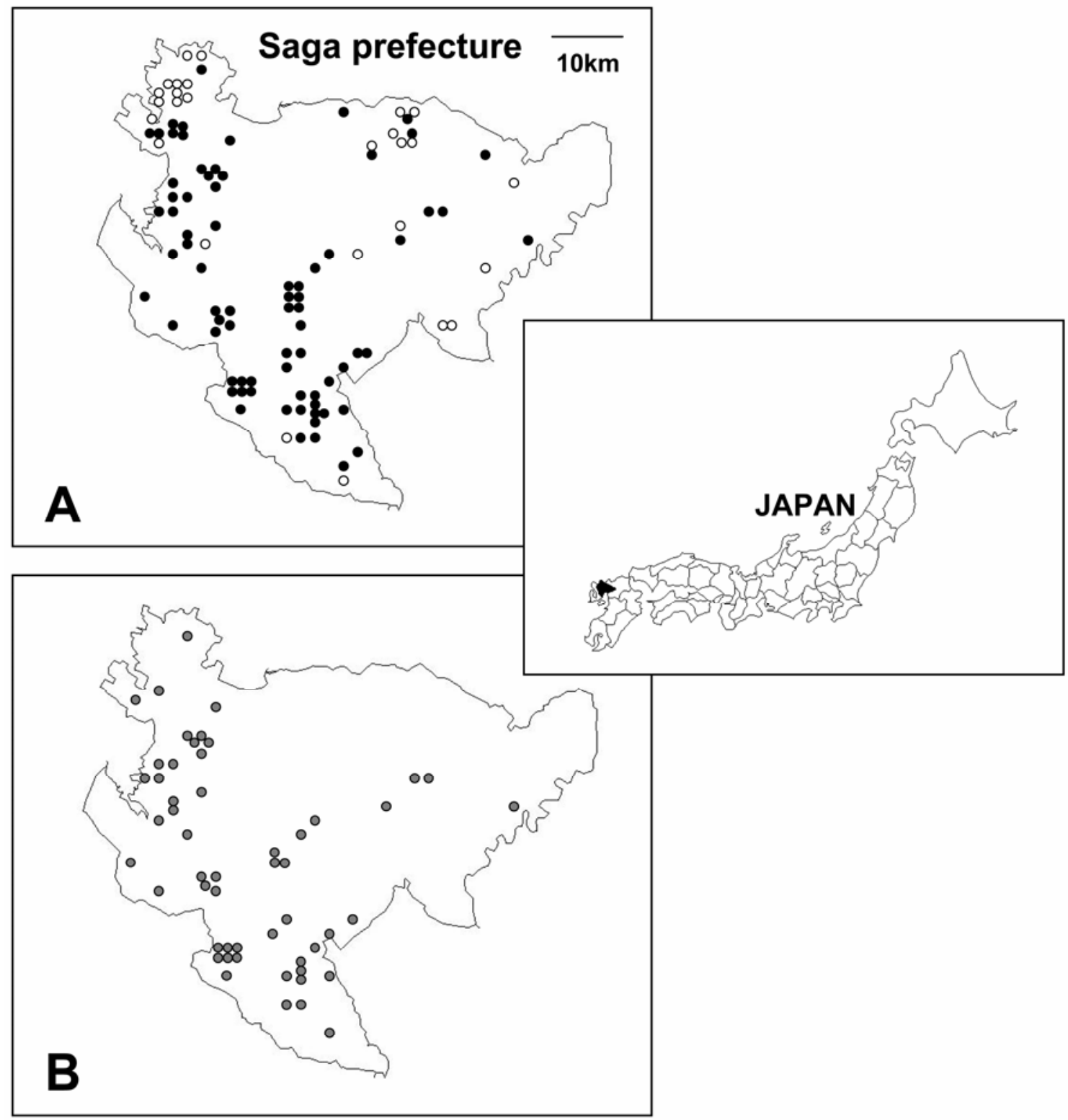

Fig. 1. Pyricularia grisea collection sites in Saga prefecture, Japan, in 2002. The shaded area on the map shows the location of Saga. A, A total of 102 sampling sites are indicated on the map of Saga prefecture. Open circles show sites where all isolates obtained were sensitive to melanin biosynthesis inhibitors targeting scytalone dehydratase (MBI-D); solid circles show sites where at least one resistant isolate was obtained. B, Gray circles indicate the distribution of haplotype Sa4 based on repetitive element-based polymerase chain reaction (rep-PCR) analysis. Isolates of haplotype Sa4 were resistant to MBI-D fungicides and predominant among the rice blast population of Saga prefecture. 
gerprint patterns were frequently observed across several prefectures. Therefore, the haplotype designations are given for each fingerprint pattern based on the prefecture name from which they were first identified. On the basis of haplotype data, resistant isolates for each prefecture possessed relatively high haplotypic diversity $(H=0.31$ to 0.80 ; Table 1$)$, although it tended to be slightly lower than that of total isolates. When calculated for the entire population of Kyushu in 2003, the haplotypic diversities of resistant isolates approximated those of the total isolates (Table 1).

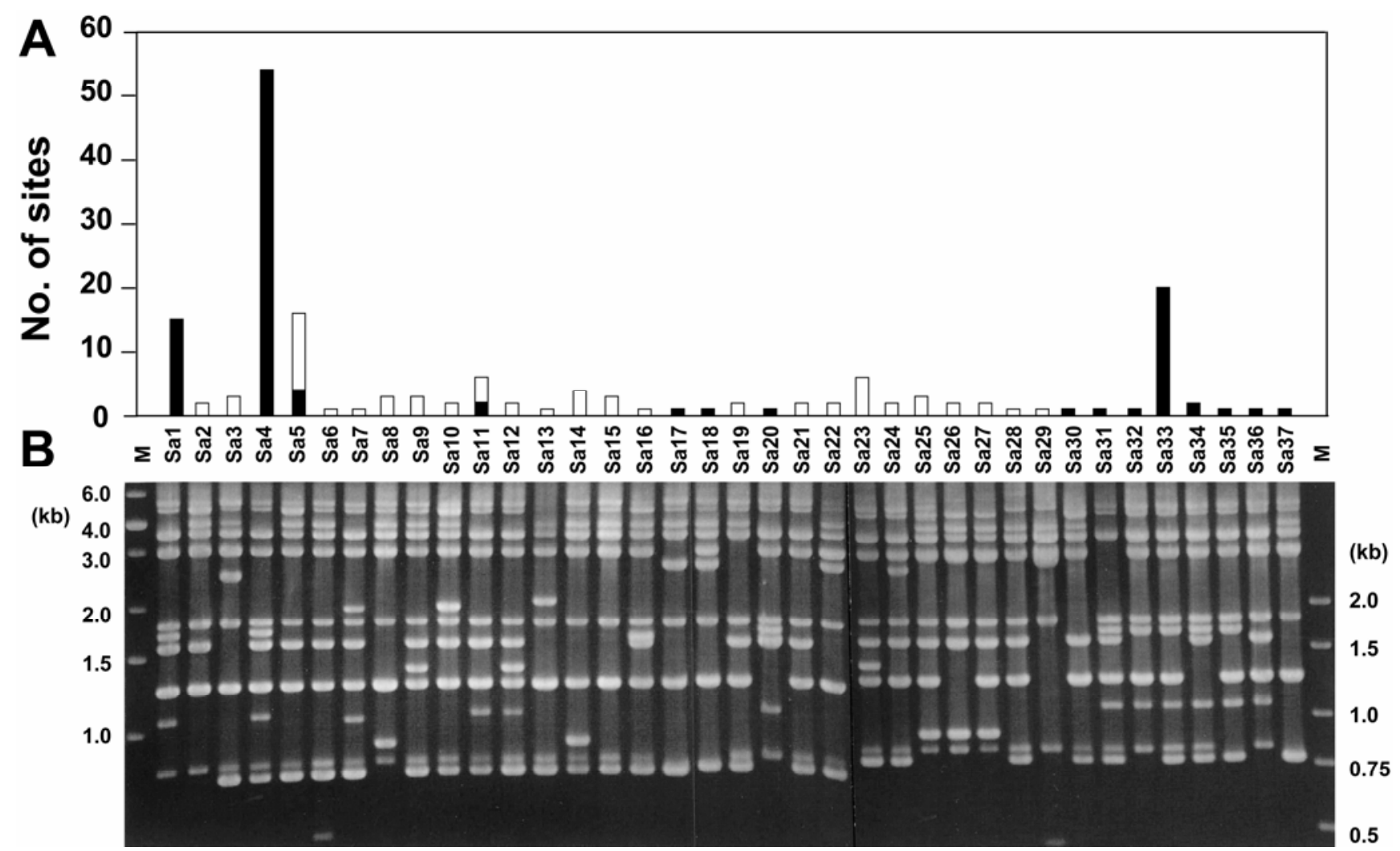

Fig. 2. Genetic structure of Pyricularia grisea population of Saga prefecture in 2002 by repetitive element-based polymerase chain reaction (rep-PCR) fingerprinting using a single primer, Pot2-TIR. A, Number of sites indicated for each haplotype based on rep-PCR fingerprints by a bar chart combined with data for diagnosis of melanin biosynthesis inhibitors targeting scytalone dehydratase (MBI-D): $\square$, white bars indicate number of sites where MBI-Dsensitive isolates were obtained; $\mathbf{m}$, black bars indicate number of sites where MBI-D-resistant isolates were obtained. B, Agarose gel showing fingerprint patterns of 37 haplotypes of $P$. grisea from Saga in 2002 generated by rep-PCR using the Pot2-TIR primer. Individual haplotypes, designated as Sa1 to Sa37, are indicated above each lane.

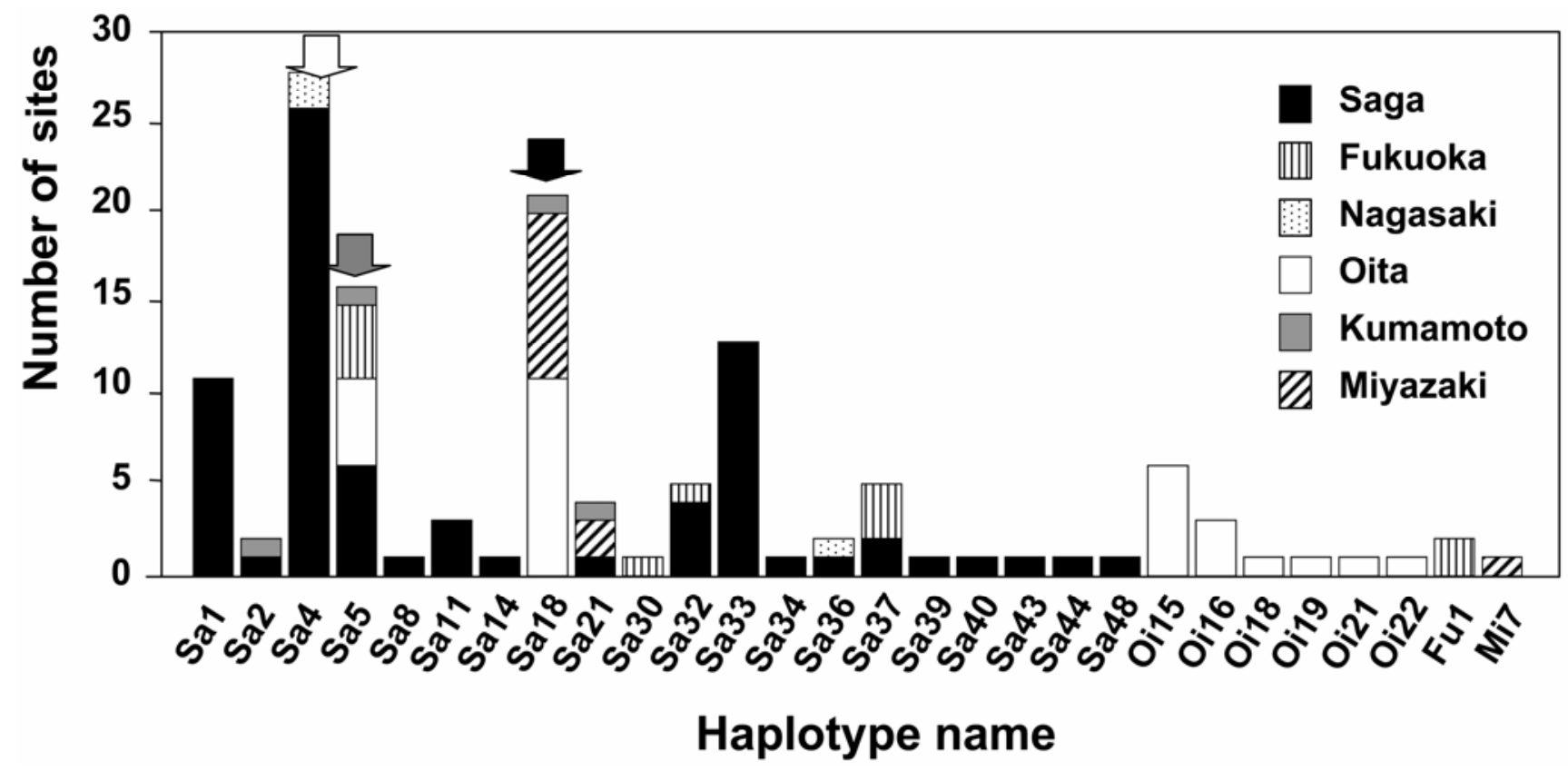

Fig. 3. Number of collection sites for each haplotype of isolates resistant to melanin biosynthesis inhibitors that target scytalone dehydratase (MBI-D) detected in six prefectures of Kyushu in 2003. Three predominant haplotypes of resistant isolates are indicated by arrows. 
In the case of Saga prefecture in 2003, rep-PCR analysis identified 35 haplotypes among the 286 isolates collected from 64 paddy fields (Tables 1 and 2). The 158 isolates resistant to MBI-D fungicide were separable into 18 distinct haplotypes, among which $\mathrm{Sa} 4$ was also predominant as in 2002. In addition, several haplotypes such as Sa1 and Sa33 among resistant isolates were also observed at a relatively high frequency throughout the same period. Among the sensitive iso-

Table 2. Numbers of sites where Pyricularia grisea isolates were collected for each haplotype in six prefectures in 2003

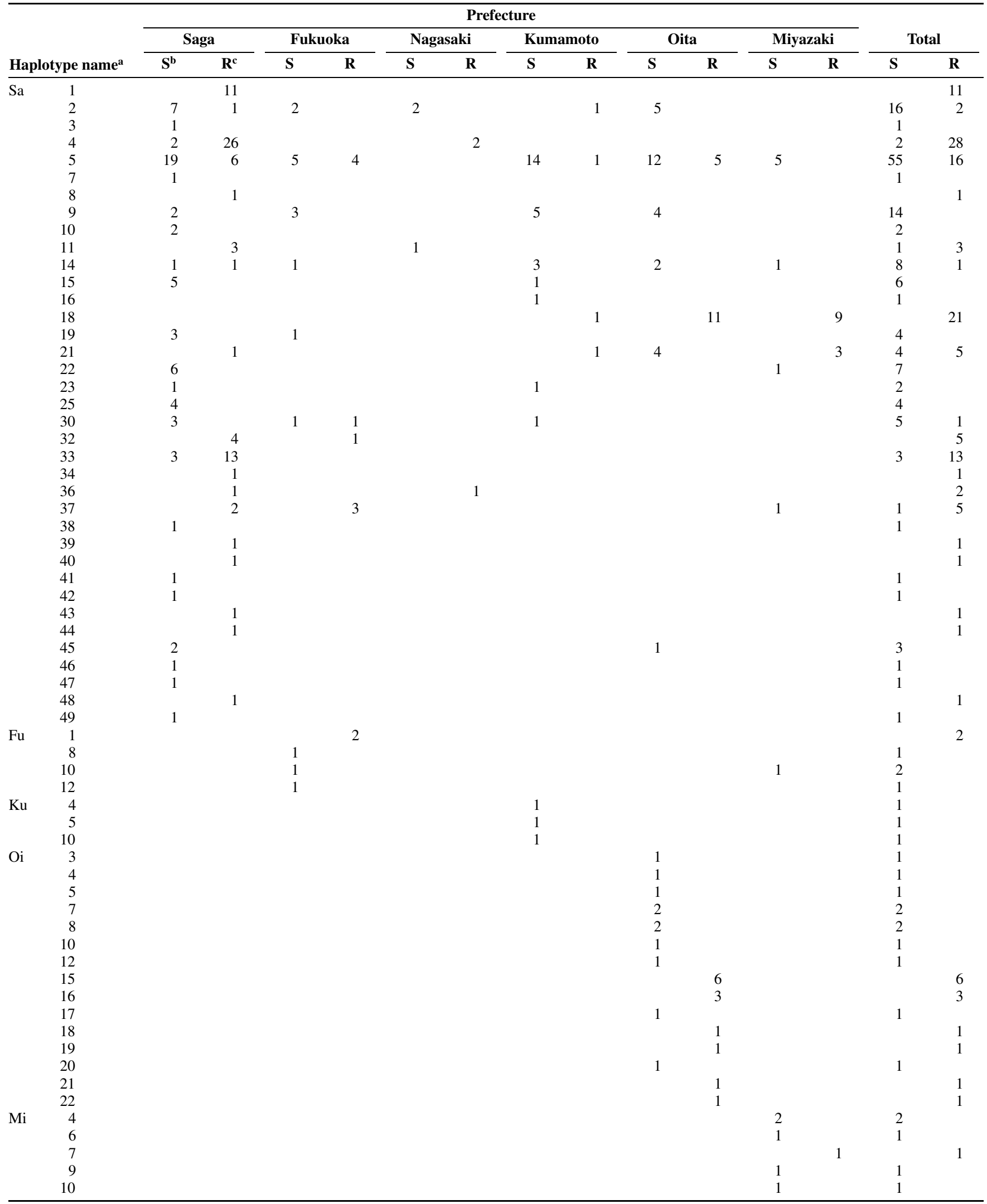

${ }^{a}$ Haplotype designations are given for each fingerprint pattern based on the prefecture name from which they were first identified.

${ }^{\mathrm{b}} \mathrm{S}=$ number of sites where sensitive isolates were obtained for each haplotype.

${ }^{\mathrm{c}} \mathrm{R}=$ number of sites where resistant isolates were obtained for each haplotype. 
lates, Sa5 was found at high frequency in 2003.

In the six prefectures of Kyushu in 2003, MBI-D-resistant isolates were classified into 28 different haplotypes (Fig. 3). Among them, it seemed likely that three haplotypes-Sa4, Sa5, and Sa18-were predominant, while most haplotypes were observed in one or few prefectures at relatively low frequency. When the sites from which the three predominant haplotypes had been isolated were indicated on a map of Kyushu based on the 2003 data from six prefectures, the distribution regions of each haplotype lay within each of three circles, respectively (Fig. 4). Although Sa4 was the predominant haplotype in Saga, it was not observed in other prefectures except for Nagasaki, accounting for $41 \%$ $(28 / 68)$ of the sites in this region. On the other hand, Sa18 was the predominant haplotype in Oita and Miyazaki, account- ing for $48 \%(20 / 42)$ of the sites in this region. Sa18 had been first detected at one site in Saga prefecture in 2002, but it was not detected in Saga prefecture in 2003. $\mathrm{Sa} 5$ of resistant isolates was widely distributed in four prefectures (Figs. 3 and 4, Table 2).

Cluster analysis based on DNA fingerprints. A phenogram constructed with the UPGMA using the data obtained by rep-PCR fingerprinting is presented in Figure 5. A close relationship was observed among all 76 haplotypes (less than 0.11 ), and there were no significant bootstrap values. At a similarity level of 0.9, the phenogram showed two main groups of haplotypes, designated Group KP-I and Group KP-II, which were not correlated with geographic distribution. Group KP-I included most of the isolates-1,142 out of $1,175(97.2 \%)$ - and all of the resistant isolates. Since KP-I contained both resis- tant and sensitive isolates, this analysis showed that the isolate clustering was not based on the presence of the SDH mutation conferring resistance. Although the representatives of the three predominant haplotypes of resistant isolates (indicated by arrows in Figure 5) were clustered separately within the KP-I group, they showed only minor differences with similarity of more than 0.92 .

\section{DISCUSSION}

In the present study, a large number of isolates were collected from the Kyushu area during 2002 and 2003, and $71.8 \%$ of the isolates collected from Saga prefecture in 2002 were found to be resistant to MBI$\mathrm{D}$ fungicides. Also, $46.2 \%$ of the isolates collected from six prefectures of Kyushu in 2003 were resistant. These results indicate that rapid development and spread of resistance occurred in Kyushu only 3 to 5

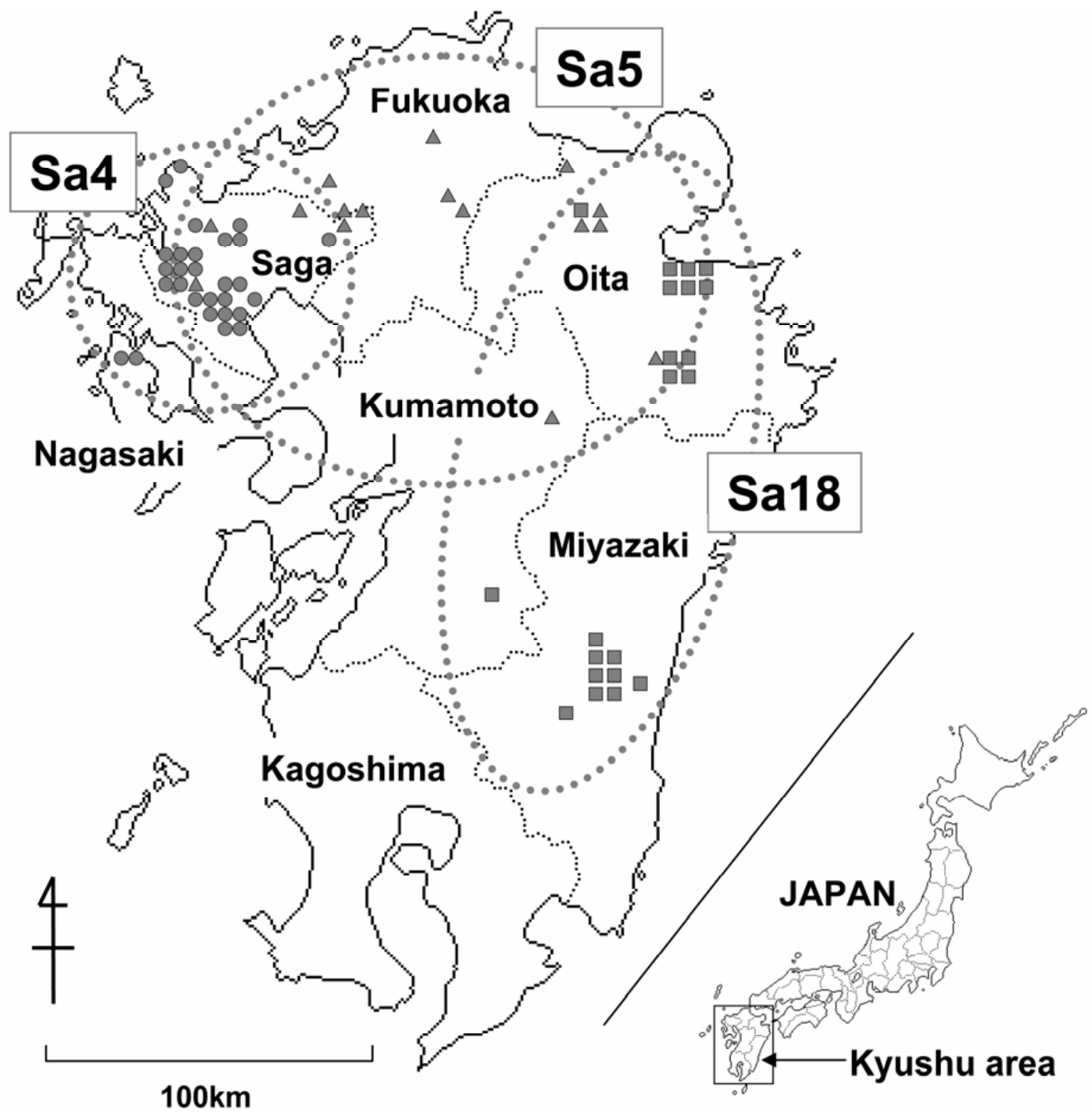

Fig. 4. Distribution of three predominant haplotypes in Kyushu in 2003: $\bullet$, sites where Sa4 was detected; $\boldsymbol{\Lambda}$, sites where Sa5 was detected; $\mathbf{m}$, sites where Sa18 was detected. Distribution areas for each haplotype are enclosed by dotted line. The location of Kyushu is represented on the map of Japan. 
years after the introduction of MBI-D fungicides, from which it may be inferred that blast pathogen populations in Japan may have a high risk of developing resistance to MBI-D fungicides. After 2003, development of resistant isolates was actually reported from several other prefectures located in the Kinki, Chugoku, Shikoku, Kanto, and Tohoku areas, i.e., outside Kyushu (24,26).

It has been considered that strains resistant to fungicides inhibiting secondary metabolism, such as the fungal melanin biosynthetic pathway, may not appear. Therefore, an outbreak of MBI-D fungicide resistance indicates that any sitespecific inhibitors may have a high potential risk for resistance development in pathogen populations. The rapid development of resistance may be due partly to the long-term residual effect of carpropamid, and partly to the way that fungicide is applied to nursery boxes. Fungicides with a long-term residual effect will further

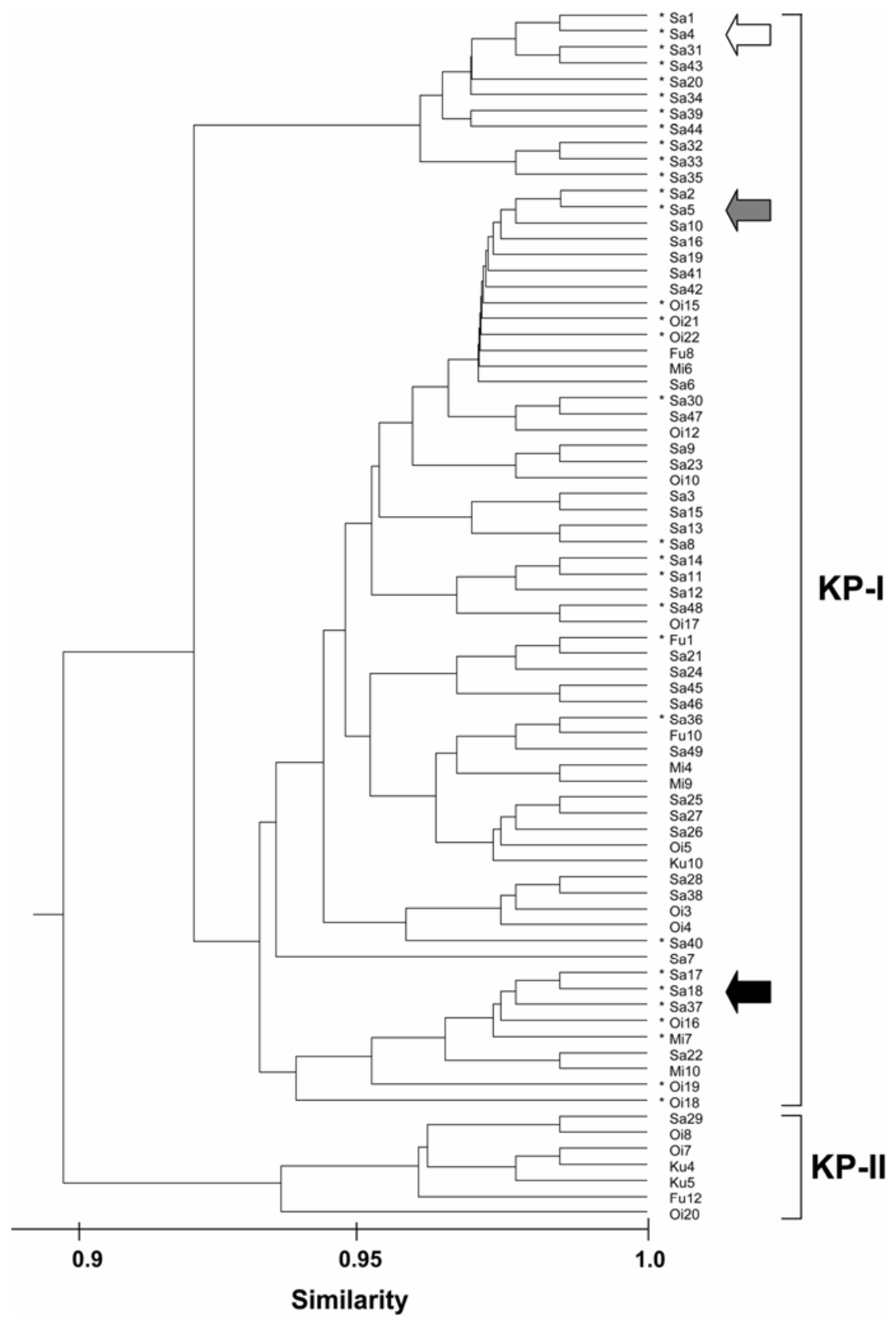

Fig. 5. Unweighted pair-group method with arithmetic averages (UPGMA) phenogram of Pyricularia grisea isolates collected from Kyushu based on fingerprint data with repetitive element-based polymerase chain reaction (rep-PCR) using a single primer, Pot 2. Haplotype designations are indicated on the right side. Scale bar indicates the horizontal distance corresponding to genetic similarity as measured by a simple matching coefficient. Two groups (KP-I and Kp-II) were identified in this tree on the basis of $>90 \%$ DNA profile similarity. Asterisks show the haplotypes that contain isolates resistant to melanin biosynthesis inhibitors that target scytalone dehydratase. Three predominant haplotypes of resistant isolates are indicated by arrows. increase the selection pressure, and consequently the sensitive isolates will decrease while resistant isolates survive and multiply without competition from sensitive isolates. Since the raising of seedlings in nursery boxes is carried out under hightemperature and high-humidity conditions using a high seedling rate, such conditions also favor the occurrence and rapid increase of resistant isolates.

We employed rep-PCR analysis using a single primer based on the Pot 2 terminal inverted repeat sequence (31) to investigate the genetic background of MBI-Dresistant isolates collected during 2002 and 2003. Based on this analysis, we detected 31 haplotypes from 647 resistant isolates tested. This indicates that SDH mutation for MBI-D resistance has arisen multiple times in populations of $P$. grisea, with the result that the mutation exists in multigenetic backgrounds. In addition, the haplotype diversity of resistant isolates was similar to the total diversity of the entire population during 2002 and 2003. These results indicate that resistant isolates had already obtained high genetic diversity equal to that of the population of sensitive isolates soon after the introduction of MBI-D fungicides. However, resistant isolates have not been detected among collections prior to 2000 (data not shown). If resistant isolates already had been present in the pathogen population before this fungicide was introduced, this mutation may not contribute to the pathogen's ability to survive and multiply under MBI-Dfree conditions. Furthermore, resistance may develop naturally in the pathogen through random and infrequent mutations because no evidence has been presented to demonstrate mutation induced by MBI-D treatment.

Although a large number of haplotypes were detected from MBI-D-resistant isolates, predominant haplotypes possessing the ability to multiply and spread appeared to be relatively limited. Also, there were regional differences in the predominant haplotypes of each population. Haplotype $\mathrm{Sa} 4$ was observed frequently in Saga between 2002 and 2003, but was not detected in other prefectures except for Nagasaki, whereas Sa18 was the predominant haplotype in Oita and Miyazaki. On the other hand, Sa5 was widely distributed among the four prefectures. It is likely that these three haplotypes mainly contributed to the spread of MBI-D-resistant isolates in Kyushu. We also confirmed that these three haplotypes were distinguishable by microsatellite marker analysis (data not shown), which demonstrated the effectiveness of fingerprint analysis using the Pot 2 rep-PCR technique. Further work will be needed to clarify the mechanisms that can influence the population diversity of rice blast fungus, e.g., to determine whether genetic recombination, such as that in asexual events, contributes to the occur- 
rence of new haplotypes in field conditions, and to evaluate the frequency of transposition of transposable elements.

UPGMA analysis of rep-PCR fingerprinting data indicated a close relationship among $P$. grisea isolates, including both resistant and sensitive ones, from Kyushu at a lineage level of over $89 \%$ similarity. In a previous study, six lineages were identified from a collection including reference and field isolates from Japan on the basis of rep-PCR fingerprint data with the Pot 2 primer (31). Although six lineages have been identified in the Japanese populations, only one clonal lineage, designated lineage $\mathrm{B}$, has been observed in contemporary populations (31). Also, it has been reported that field isolates collected from Japan in recent years belonged to a limited number of lineages $(5,30)$. Therefore, all isolates collected in the present study appear to belong to only one clonal lineage corresponding to lineage $\mathrm{B}$ (in agreement with lineage JBLA-K04 in Sone et al. [30]). Lineage B appears to be the most highly adapted to the Japanese ricegrowing environment in recent times. Occupation of a specific lineage may be correlated with the distribution of the limited number of host cultivars possessing resistance genes such as Pi- $a$ and Pi-i. Consequently, most recent field isolates have been found to belong to one specific race, 007, which is able to infect all of the major rice cultivars such as Koshihikari, Hitomebore, and Hinohikari. These may serve as bottlenecks to lineage diversity among $P$. grisea isolates obtained recently from Japan. The fact that resistant and sensitive isolates are clustered together into one closely related group appears to indicate that the SDH mutation conferring resistance had occurred randomly within lineage B after separation of the population structure.

Thus, isolates possessing SDH mutation would have been selected and rapidly spread in each region of Kyushu in a short time as a result of widespread fungicide use. Also, it was demonstrated that rapid development of resistance in Kyushu was not caused solely by an origin in Saga. If a resistant population had already been established throughout Japan prior to MBI-D fungicide use, the reason for the rapid appearance of fungicide resistance in Kyushu is still unclear. However, as Kyushu has a climate that is well suited to rice cultivation for a long period of the year (about 8 months), transplanting and harvesting of rice are possible at various times. Another factor is that some farmers often save seed from their harvest for sowing the following year. Because the blast pathogen can infect at any growth stage of the rice plant and carry over to the following year by infected seed, these circumstances might accelerate generation alternation of the blast pathogen and lead to the rapid development of resistance. Further research on temporal changes in population structure would provide important information for resistance risk assessment and validation of appropriate strategies for use of MBI-D fungicides to control $P$. grisea.

\section{ACKNOWLEDGMENTS}

We thank the numerous staff of prefectural Agricultural Research Centers and Plant Protection Offices located in each of seven prefectures of Kyushu-Saga, Fukuoka, Nagasaki, Kumamoto, Oita, Miyazaki, and Kagoshima-for their help in sampling of $P$. grisea isolates; Bayer CropScience and SUMITOMO CHEMICAL for cooperation in gene diagnosis of MBI-D resistance.

\section{LITERATURE CITED}

1. Bell, A. A., and Wheeler, M. H. 1986. Biosynthesis and functions of fungal melanins. Annu. Rev. Phytopathol. 24:411-451.

2. Butler, M. J., Day, A. W., Henson, J. M., and Money, N. P. 2001. Pathogenic properties of fungal melanins. Mycologia 93:1-8.

3. Correll, J. C., Harp, T. L., Guerber, J. C., Zeigler, R. S., Liu, B., Cartwright, R. D., and Lee, F. N. 2000. Characterization of Pyricularia grisea in the United States using independent genetic and molecular markers. Phytopathology 90:1396-1404.

4. Couch, B. C., and Kohn, L. M. 2002. A multilocus gene genealogy concordant with host preference indicates segregation of a new species, Magnaporthe oryzae from M. grisea. Mycologia 94:683-693.

5. Don, L. D., Kusaba, M., Urashima, A. S., Tosa, Y., Nakayashiki, H., and Mayama, S. 1999. Population structure of the rice blast fungus in Japan examined by DNA fingerprinting. Ann. Phytopathol. Soc. Jpn. 65:15-24.

6. Felsenstein, J. 1989. Phylogeny inference package. Cladistics 5:164-166.

7. Froyd, J. D., Paget, C. J., Guse, L. R., Dreikorn, B. A., and Pafford, J. L. 1976. Tricyclazole - New systemic fungicide for control of Pyricularia oryzae on rice. Phytopathology 66: $1135-1139$

8. George, M. L. C., Nelson, R. J., Zeigler, R. S., and Leung, H. 1998. Rapid population analysis of Magnaporthe grisea by using rep-PCR and endogenous repetitive DNA sequences. Phytopathology 88:223-229.

9. Howard, R. J., and Valent, B. 1996. Breaking and entering: Host penetration by the fungal rice blast pathogen Magnaporthe grisea. Annu. Rev. Microbiol. 50:491-512.

10. Inoue, S., Maeda, K., Uematsu, T., and Kato, T. 1984. Comparison of tetrachlorophthalide and pentachlorobenzyl alcohol with chlobenthiazone and other melanin inhibitors in the mechanism of rice blast control. J. Pestic. Sci. 9:731-736.

11. Javan-Nikkhah, M., McDonald, B. A., Banke, S., and Hedjaroude, G. A. 2004. Genetic structure of Iranian Pyricularia grisea populations based on rep-PCR fingerprinting. Eur. J. Plant Pathol. 110:909-919.

12. Kachroo, P., Leong, S., and Chattoo, B. B. 1994. Pot2, inverted repeat transposon from the rice blast fungus Magnaporthe grisea. Mol. Gen. Genet. 245:339-348.

13. Kaku, K., Takagaki, M., Shimizu, T., and Nagayama, K. 2003. Diagnosis of dehydratase inhibitors in melanin biosynthesis inhibitor (MBI-D) resistance by primer-introduced restriction enzyme analysis in scytalone dehydratase gene of Magnaporthe grisea. Pest Manag. Sci. 59:843-846.

14. Kurahashi, Y. 2001. Melanin biosynthesis inhibitors (MBIs) for control of rice blast. Pestic. Outlook Feb. 32-35.

15. Kurahashi, Y., Hattori, T., Kagabu, S., and
Pontzen, R. 1996. Mode of action of the novel rice blast fungicide KTU 3616. Pestic. Sci. 47:199-200.

16. Kurahashi, Y., Kurogochi, S., Matsumoto, N. and Kagabu, S. 1999. Development of a new rice blast controlling agent, carpropamid. J. Pestic. Sci. 24:204-216.

17. Kurahashi, Y., Sakawa, S., Kinbara, T., Tanaka, K., and Kagabu, S. 1997. Biological activity of carpropamid (KTU 3616): A new fungicide for rice blast disease. J. Pestic. Sci. 22:108-112.

18. Manabe, A., Maeda, K., Enomoto, M., Takano, H., Katoh, T., Yamada, Y., and Oguri, Y. 2002. Synthesis and fungicidal activity of acyanoacetamide derivatives: Discovery of a new rice blast fungicide, diclocymet (S-2900). J. Pestic. Sci. 27:257-266.

19. Motoyama, T., Imanishi, K., Kinbara, T., Kurahashi, Y., and Yamaguchi, I. 1998. Inhibition of scytalone dehydratase in melanin biosynthesis by carpropamid, a novel rice blast controlling agent. J. Pestic. Sci. 23:58-61.

20. Motoyama, T., Kagabu, S., Matsuoka, M., and Yamaguchi, I. 2002. Differential inhibition of a melanin biosynthetic enzyme scytalone dehydratase by carpropamid, a fungicide for rice blast control, and its isomers. J. Pestic. Sci. 27:141-144

21. Muramatsu, K., Fuji, S., Furuya, H., and Naito, H. 2003. Population structure of rice blast fungus prevalent in Akita prefecture in 2000 and 2002. Annu. Rep. Plant Prot. North Jpn. 54:1822.

22. Nakasako, M., Motoyama, T., Kurahashi, Y., and Yamaguchi, I. 1998. Cryogenic X-ray crystal structure analysis for the complex of scytalone dehydratase of a rice blast fungus and its tight-binding inhibitor, carpropamid: The structural basis of tight-binding inhibition. Biochemistry 37:9931-9939.

23. Nei, M. 1973. Analysis of gene diversity in subdivided populations. Proc. Natl. Acad. Sci. USA 70:3321-3323

24. Osada, Y., Kyuno, T., and Takagi, H. 2004 Development of Pyricularia grisea isolates with decreased sensitivity to MBI-D in Hyogo prefecture. Proc. Kansai Plant Prot. 46:111.

25. Rossman, A. Y., Howard, R. J., and Valent, B. 1990. Pyricularia grisea, the correct name for the rice blast disease fungus. Mycologia 82:509-512.

26. Sasaki, N., Iwadate, Y., Tominaga, T., and Katsube, K. 2005. Occurrence of MBI-D resistant strain of Pyricularia grisea in Iwate prefecture. Annu. Rep. Plant Prot. North Jpn. 55:205

27. Sawada, H., Sugihara, M., Takagaki, M., and Nagayama, K. 2004. Monitoring and characterization of Magnaporthe grisea isolates with decreased sensitivity to scytalone dehydratase inhibitors. Pest Manag. Sci. 60:777-785.

28. Selander, R. K., Mckinney, R. M., Whittam, T. S., Bibb, W. F., Brenner, D. J., Nolte, F. S., and Pattison, P. E. 1985. Genetic structure of populations of Legionella pneumophila. J. Bacteriol. 163:1021-1037.

29. So, K., Fuji, M., Iwabuchi, H., Kanayama, M., and Yamaguchi, J. 2002. Effects of various fungicides against less carpropamid-sensitive rice blast fungus isolated from the northwest area in Saga Prefecture. Jpn. J. Phytopathol. 68:262.

30. Sone, T., Abe, T., Yoshida, N., Suto, M., and Tomita, F. 1997. DNA fingerprinting and electrophoretic karyotyping of Japanese isolates of rice blast fungus. Ann. Phytopathol. Soc. Jpn. 63:155-163.

31. Suzuki, F., Arai, M., and Yamaguchi, J. 2006. DNA fingerprinting of Pyricularia grisea by rep-PCR using single primers designed from the terminal inverted repeat of each of the transposable elements Pot 2 and MGR586. J. Gen. Plant Pathol. 72:314-317. 
32. Takagaki, M., Kaku, K., Watanabe, S., Kawai, K., Shimizu, T., Sawada, H., Kumakura, K., and Nagayama, K. 2004. Mechanism of resistance to carpropamid in Magnaporthe grisea. Pest Manag. Sci. 60:921-926.

33. Woloshuk, C. P., and Sisler, H. D. 1982. Tricyclazole, pyroquilon, tetrachlorophthalide, pcba, coumarin and related-compounds inhibit melanization and epidermal penetration by Pyricularia oryzae. J. Pestic. Sci. 7:161-166.
34. Yamada, N., Motoyama, T., Nakasako, M., Kagabu, S., Kudo, T., and Yamaguchi, I. 2004. Enzymatic characterization of scytalone dehydratase Val75Met variant found in melanin biosynthesis dehydratase inhibitor (MBI-D) resistant strains of the rice blast fungus. Biosci. Biotechnol. Biochem. 68:615-621.

35. Yamaguchi, I., and Fujimura, M. 2005. Recent Topics on Action Mechanisms of Fungicides. J. Pestic. Sci. 30:67-74.
36. Yamaguchi, J., Kuchiki, F., Hirayae, K., and So, K. 2002. Decreased effect of carpropamid for rice blast control in the west north area of Saga Prefecture in 2001. Jpn. J. Phytopathol. 68:261.

37. Yap, I. V., and Nelson, R. J. 1996. Winboot: A program for performing bootstrap analysis of binary data to determine the confidence limit of UPGMA-based dendrograms. IRRI Discussion Paper Series No. 14. Manila, Philippines. 